\section{Pruning Height and Selective Limb Removal Affect Yield of Large 'Hass' Avocado Trees}

\author{
T.G. Thorp ${ }^{1}$ \\ The Horticulture and Food Research Institute of New Zealand Ltd., Private \\ Bag 92 169, Auckland, New Zealand

\section{B. Stowell} \\ The Horticulture and Food Research Institute of New Zealand Ltd., R.D. 2, \\ Te Puke, New Zealand
}

Additional index words. Persea americana, fruit size, crop load, alternate bearing

\begin{abstract}
Avocado (Persea americana Mill. cv. Hass) trees were pruned over 3 years at either 4 or $6 \mathrm{~m}$ in height by removing or heading back selected limbs. Yields were compared with those from control trees with no pruning in the upper canopy. All trees had similar crop loads before pruning. Trees were at $9 \times 10$-m spacing and were 8 years old when first pruned. Fruit yields were recorded for 2 years before the first pruning and then in each year of pruning. In the final year, trees were harvested in four height zones: $0-2 \mathrm{~m} ; 2-4 \mathrm{~m}$; 4-6 m; and >6 m. Cumulative yields over 3 years were similar on 6-m and control trees, but were less on 4-m trees due to the large volume of fruiting canopy removed in the first pruning. The height of the main fruiting zone was lowered on the 4-m trees, with yields in the 2-4-m zone similar to those in the 4-6-m zone of the control trees. Pruning to reduce the number and length of scaffold branches increased fruit yields on the remaining scaffolds without reducing fruit size. Results are discussed in terms of harvest efficiency and the benefits of small tree orchard systems.
\end{abstract}

Large tree size and inconsistent fruit yields are major expenses for avocado growers. Large trees contribute to severe shading and restricted access within orchards. In crowded orchards, lower branches become nonproductive and fruiting sites become restricted to the upper canopy zones. When this happens, orchards are usually thinned by removing alternate trees or by severe pruning to produce a "stag horn" effect. Both practices result in dramatic shortterm reductions in yield. To reduce tree size and maintain reliable fruit yields we need a basic understanding of the influence of canopy architecture on productivity and of the physiological responses to canopy manipulations such as pruning. While we have good knowledge of these factors for crops such as apples (Malus $\times$ domestica Borkh.), our experience with avocados is much less sophisticated. This paper provides some results from studies attempting to address these issues.

The Rauh architectural tree model, to which the avocado conforms, provides a simple blueprint for tree growth (Hallé et al., 1978; Thorp, 1993). Growth is monopodial and orthotropic,

\footnotetext{
Received for publication 14 Apr. 2000. Accepted for publication 16 Sept. 2000. This research was partially supported by funding from the New Zealand Foundation for Research, Science, and Technology. We thank R. Bagshaw and Goldwood Orchard for providing access to their orchard for this study. The cost of publishing this paper was defrayed in part by the payment of page charges. Under postal regulations, this paper therefore must be hereby marked advertisement solely to indicate this fact.

${ }^{1}$ To whom requests for reprints should be addressed. E-mail address: gthorp@hortresearch.co.nz
}

with multiple axes forming on disruption of the monopodial axis by either pruning or mechanical damage. Branching is either sylleptic or proleptic with the ratio of each of these affecting tree growth habit (Thorp and Sedgley, 1993). In the cultivar Hass, both shoot types contribute to final tree form, with mature trees tending to produce several large, mutually shading, scaffold branches. This growth habit contrasts with that of the cultivar Sharwill in which a dominance of prolepsis results in an open spreading tree, and the cultivar Reed, in which a dominance of syllepsis gives a columnar growth habit. Different pruning techniques would be required for each of these growth habits.

Using the Rauh model as a framework, the options to manipulate 'Hass' tree structure to benefit fruit production appear straightforward. A simple reduction in branch number to reduce internal shading should increase productivity, as would a single axis tree in high density plantations. In our research we have been developing methods to produce a single axis tree through stimulation of sylleptic growth in the nursery and during the first $2-3$ years in the field. The alternative option, to restructure larger trees and to reduce mutual shading between scaffold branches, is the focus of research presented here.

Compared with other tree fruit crops, relatively few avocado pruning trials have been reported in the scientific literature. Most information for this crop is presented as industry articles based upon casual observations and often without supporting data or adequate controls, especially with 'Hass' the dominant commercial cultivar (Stassen et al., 1999). Gaillard (1971) described the start of a detailed tree training investigation involving complex cordon and palmette systems, but apparently no yield data has been reported. Warneke et al. (1972) reported reduced yields in the year of pruning (topping) 'Bacon' trees, but with yields almost back to normal in the following year. Bertin (1976) and Crane et al. (1992), working with large 'Lula' and 'Booth 8 ' trees, found that topping increased yields, as did Ashenkasi (1984) working with 'Hass' and 'Ettinger'. Mutual shading between trees prior to topping was an important factor determining subsequent yields. For example, Goodall (1954) and Crane et al. (1992) found that topping increased yields more if trees were widely spaced before pruning than if they were crowded. Farré et al. (1987) reported the results of pruning research to reduce flower numbers and thus influence biennial bearing, but not tree stature. More recently, Stassen and Snijder (1999) discussed pruning options for intensive avocado plantings and presented preliminary yield data from young trees.

The objective of our research was to compare the effects of pruning height and selective limb removal on fruit yields and on the spatial distribution of fruit within canopies of large, vigorously growing 'Hass' avocado trees. We had three pruning objectives: 1) reduce tree height to bring the main fruiting zone closer to the ground to reduce harvesting costs; 2) reduce the number of large scaffold branches to reduce their mutual shading and thus increase their productivity; and 3) maintain consistent tree yields over the long-term.

\section{Materials and Methods}

'Hass' trees grafted onto 'Zutano' seedling rootstock, growing in a single orchard block on a commercial property in the northern Bay of Plenty, New Zealand (lat. $37^{\circ} \mathrm{S}$, long. $176^{\circ} \mathrm{E}$ ), were used in this study. Free-draining, sandy loam soils and high annual rainfall $(1300 \mathrm{~mm})$ in this region result in rapid plant growth and large tree size. Trees were planted in 1986 at $5 \times 7 \mathrm{~m}$ spacing and in 1991 were thinned on the diagonal to give a final spacing of $9 \times 10 \mathrm{~m}$. In 1992, equal numbers of low, medium and high cropping trees were selected using a visual estimate of crop load. Actual tree yields were recorded at the time of commercial harvest in 1992 and 1993, so that all trees had a known cropping history before pruning treatments were commenced in 1994.

Prior to treatment, trees were 5-8 $\mathrm{m}$ tall and each tree had 8-12 large scaffold branches. Trees were first pruned in Feb./ Mar. (late summer) 1994. To minimize shading from adjacent treatments, pruning treatments were applied to blocks of 10 trees $(\approx 0.1$ ha each), with two blocks per treatment. All treatment blocks were located in the same orchard area, which was divided in half and each treatment applied once in each half, excluding trees at the ends of each row. Initial pruning on all trees involved the removal of lower branches that were growing out into the center of the row and preventing machinery access. Three 
treatments were then set up: an "unpruned" control and two treatments with trees pruned at two heights, 4 and $6 \mathrm{~m}$. In the latter two treatments, the number of large scaffold branches was reduced to 6-8, evenly spaced branches in the tree. The aim here was to thin the canopies, just as you would thin an orchard block by removing whole trees. These pruning cuts were all made flush with the parent axis to reduce the amount of regrowth from around the cut surface. The remaining branches were then headed back to strong lateral growths at $\approx 4$-m or 6-m in height, according to treatment. In subsequent years $(1995,1996)$, tree heights were maintained to within $0.5 \mathrm{~m}$ of the treatment height, with some further branch removal in the upper canopy. This maintenance pruning was also undertaken in late summer.

Eight trees from each treatment (four trees from each of two treatment blocks containing 10 trees each) were selected for measurement. Trees were selected from the center of each block to avoid border effects. To reduce the influence of alternate bearing we used previous years' data to exclude trees with extremely low or high fruit yields. On each tree, we selected six scaffold branches and identified the three previous annual growth sections (1989-92) along the primary growth axes to ensure that we had consistent fruiting units for recording fruit yield per branch (Thorp and Sedgley, 1993). On each branch we marked the start of the 1989 growth section and all fruit harvests were from locations beyond this mark. Before application of pruning treatments we recorded the length of each annual growth section along the primary growth axis. Number and weight of fruit per branch and total weight of fruit per tree were recorded in each year (1992-96). In the final year, we mechanically graded all fruit into commercial size grades, with $18,20,23,25,28$, or 32 fruit per $5.5-\mathrm{kg}$ tray, to give the number of tray equivalents per tree or branch.

The statistical design was completely randomized with eight tree replicates per pruning treatment. For analysis of variance (ANOVA), $a^{M_{I N I T A B}}{ }^{\mathrm{TM}}$ (R. 12.1) was used, with mean separation by the Tukey-Kramer method with a family error rate of 0.05 .

\section{Results}

All trees had similar crop loads in 1992 and 1993, before pruning (Table 1). In the first year after pruning (1994), the $6 \mathrm{~m}$ and control trees had similar crop loads. However, yields were significantly reduced on the 4-m trees in this transition year because a large quantity of fruit had been cut from these trees during pruning in February. In 1995, after 2 years of pruning and the opportunity for the more open canopies to influence flowering and fruit set, fruit yields were similar on all trees regardless of pruning treatment. In 1996, control trees had more fruit than either the 4- or 6-m trees, i.e., 236,156 , and $162 \mathrm{~kg} /$ tree, respectively. The same pattern was found in terms of tray equivalents, with the number of $5.5-\mathrm{kg}$ trays per tree being similar on the 4- and 6-m trees, but less than on the control trees (Table 2).

Table 1. Fruit yields ( $\mathrm{kg} /$ tree $)$ on 'Hass' avocado trees before and after application of pruning treatments in late Summer 1994, 1995, and 1996. Trees were left unpruned (control) or headed back to 4 or $6 \mathrm{~m}$ in Feb. and Mar. 1994.

\begin{tabular}{|c|c|c|c|c|c|c|c|}
\hline \multirow[b]{3}{*}{ Treatment } & \multirow{3}{*}{$\begin{array}{c}\text { Tree } \\
\text { age (years): }\end{array}$} & \multicolumn{2}{|c|}{ Before pruning } & \multicolumn{3}{|c|}{ After pruning } & \multirow{3}{*}{$\begin{array}{c}\text { Cumulative } \\
\text { yield } \\
\text { 1994-96 } \\
\end{array}$} \\
\hline & & 1992 & 1993 & 1994 & 1995 & 1996 & \\
\hline & & 6 & 7 & 8 & 9 & 10 & \\
\hline Control & & 128 & 105 & $229 a^{z}$ & 108 & $236 a$ & $573 \mathrm{a}$ \\
\hline 4-m pruning & & 118 & 117 & $159 \mathrm{~b}$ & 111 & $156 \mathrm{~b}$ & $426 \mathrm{~b}$ \\
\hline \multirow[t]{2}{*}{$6-\mathrm{m}$ pruning } & & 140 & 102 & $225 \mathrm{a}$ & 137 & $162 b$ & $524 \mathrm{a}$ \\
\hline & & NS & NS & $* *$ & NS & $*$ & $*$ \\
\hline
\end{tabular}

${ }^{\mathrm{z}}$ Mean separation in columns by Tukey-Kramer method, $P \leq 0.05$.

ss, ****Nonsignificant or significant at $P \leq 0.05$ or 0.01 , respectively.

Cumulative yields over 3 years (1994-96) were similar on the control and 6-m trees, with 573 and $524 \mathrm{~kg} /$ tree, respectively (Table 1). The 4-m trees had the lowest cumulative yield over this period with $426 \mathrm{~kg} /$ tree. With 111 trees per hectare at $9 \times 10 \mathrm{~m}$ spacing, these yields represent annual production of 21,19 , and $16 \mathrm{t} / \mathrm{ha}$ for the control, 6- and 4-m trees, respectively.

An important objective in this research was to encourage trees to produce more fruit in the lower canopy zones and thus reduce harvesting costs. While fruit yields in the $0-2 \mathrm{~m}$ zone were not affected by our treatments, trees pruned to $4 \mathrm{~m}$ had almost twice as many fruit in the 2-4-m zone than either the $6-\mathrm{m}$ or control trees (Table 2 ). Thus, the productivity of the 2-4-m zone was increased on the $4 \mathrm{~m}$ trees, with $80 \%$ of the crop being produced in this zone compared with just $33 \%$ and $41 \%$ in the equivalent zone on the control and 6-m trees, respectively.

There was no consistent trend in the effect of crop load on fruit size, although fruit tended to be smaller on control trees and larger on $6 \mathrm{~m}$ trees (Table 2). Also, control trees produced more undersize "reject" fruit $(<168 \mathrm{~g})$ in 1996 $(P \leq 0.001)$ than did either the 4- or 6-m trees, with 45,18 , and $14 \mathrm{~kg} /$ tree, respectively (data not shown). In the 2-4-m zone, there was a significant increase in yield from the 4-m trees, yet mean fruit weight was similar to that of the control trees. There appears to be some prospect that fruit in "well illuminated sites" may be larger irrespective of total crop load. The same trend was evident across zones in the control trees where the upper zone fruit were comparatively large.

Pruning involved reducing the number and length of large scaffold branches. This increased the productivity of remaining branches. All branches were similar in average length and basal diameter and had similar yields before application of pruning treatments (Tables 3 and 4). In 1994, even though the control and $6 \mathrm{~m}$ trees had similar yields (Table 1), large scaffold branches on $6 \mathrm{~m}$ trees had more fruit than did similar branches on control trees (Table 4). Also, in 1995, branches on 4$\mathrm{m}$ trees had nearly twice as many fruit as did similar branches on control trees, despite tree yields being similar. Unfortunately we do not have flower counts from these branches to determine if the increased yield was due to more flowers or increased fruit set. In 1996, when control trees had higher yields than 4-m or 6-m trees, fruit yields per branch were similar for all trees. Pruning treatments also

Table 2. Effects of height of pruning in 1994 on yield, average fruit size, and number of $5.5-\mathrm{kg}$ tray equivalents harvested in 1996 from four height zones (A-D) on 10-year-old 'Hass' avocado trees.

\begin{tabular}{|c|c|c|c|c|c|}
\hline \multirow[b]{2}{*}{ Treatment } & \multirow[b]{2}{*}{$\begin{array}{c}\text { Whole } \\
\text { tree }\end{array}$} & \multicolumn{4}{|c|}{ Canopy zone } \\
\hline & & $\begin{array}{c}\mathrm{A} \\
0-2 \mathrm{~m}\end{array}$ & $\begin{array}{c}\text { B } \\
2-4 \mathrm{~m}\end{array}$ & $\begin{array}{c}\mathrm{C} \\
4-6 \mathrm{~m}\end{array}$ & $\begin{array}{c}\mathrm{D} \\
>6 \mathrm{~m}\end{array}$ \\
\hline \multicolumn{6}{|c|}{ Fruit yield (kg) } \\
\hline Control & $236 \mathrm{a}^{\mathrm{z}}$ & 19 & $77 \mathrm{~b}$ & $126 \mathrm{a}$ & 14 \\
\hline 4-m pruning & $156 \mathrm{~b}$ & 17 & $125 \mathrm{a}$ & $14 \mathrm{c}$ & --- \\
\hline $6-\mathrm{m}$ pruning & $162 \mathrm{~b}$ & 11 & $67 \mathrm{~b}$ & $84 \mathrm{~b}$ & --- \\
\hline & $*$ & NS & $*$ & $* * *$ & \\
\hline \multicolumn{6}{|c|}{ Percentage of total yield (\%) } \\
\hline Control & 100 & 8 & 33 & 53 & 6 \\
\hline 4-m pruning & 100 & 11 & 80 & 9 & 0 \\
\hline 6-m pruning & 100 & 7 & 41 & 52 & 0 \\
\hline \multicolumn{6}{|c|}{ Average fruit size ( $g$ ) } \\
\hline Control & 217 & 206 & $215 \mathrm{~b}$ & $211 \mathrm{~b}$ & 243 \\
\hline 4-m pruning & 227 & 230 & $227 \mathrm{ab}$ & $236 \mathrm{ab}$ & --- \\
\hline $6-\mathrm{m}$ pruning & 249 & 234 & $258 \mathrm{a}$ & $248 \mathrm{a}$ & --- \\
\hline & NS & NS & $*$ & $*$ & \\
\hline \multicolumn{6}{|c|}{ No. of trays } \\
\hline Control & 35.3 & 3.2 & 10.9 & 19.3 & 1.9 \\
\hline 4-m pruning & 25.6 & 2.8 & 20.5 & 2.3 & --- \\
\hline 6-m pruning & 26.9 & 1.8 & 10.9 & 14.3 & --- \\
\hline
\end{tabular}


Table 3. Basal diameter and length of annual growth sections before pruning on large scaffold branches on 'Hass' avocado trees. Six branches were selected on each of eight trees per treatment. Branches were selected in 1992 when trees were 6 years old. Basal diameter of 1989 section was measured in 1992.

\begin{tabular}{lcccc}
\hline & Basal diam $(\mathrm{mm})$ & \multicolumn{3}{c}{ Annual extension growth $(\mathrm{cm})$} \\
\cline { 3 - 5 } Treatment & 1989 section & $1989-92$ & $1992-93$ & $1993-94$ \\
\hline Control & 56 & 173 & $33 \mathrm{~b}^{\mathrm{z}}$ & 39 \\
4-m pruning & 57 & 188 & $41 \mathrm{a}$ & 40 \\
6-m pruning & 57 & 175 & $35 \mathrm{ab}$ & 44 \\
& NS & NS & $*$ & NS \\
\hline
\end{tabular}

${ }^{\mathrm{z}}$ Mean separation in columns by Tukey-Kramer method, $P \leq 0.05$.

Ns, * Nonsignificant or significant at $P \leq 0.05$.

Table 4. Effects of pruning height on fruit yields per branch and average fruit size from selected branches on 'Hass' avocado trees pruned in late-summer 1994, 1995, and 1996. Trees were left unpruned (control) or headed back to 4 or $6 \mathrm{~m}$ in February/March of each year. Branches were selected in 1992 when trees were 6 years old. Only marked branches remaining in 1996 were included in analyses.

\begin{tabular}{|c|c|c|c|c|c|}
\hline \multirow[b]{2}{*}{ Treatment } & \multicolumn{2}{|c|}{ Before pruning } & \multicolumn{3}{|c|}{ After pruning } \\
\hline & 1992 & 1993 & 1994 & 1995 & 1996 \\
\hline \multicolumn{6}{|c|}{ Fruit yield per branch (kg) } \\
\hline Control & 6.9 & 3.6 & $9.5 \mathrm{~b}^{\mathrm{z}}$ & $4.4 \mathrm{~b}$ & 9 \\
\hline 4-m pruning & 6.5 & 4.6 & $10.7 \mathrm{ab}$ & $8.0 \mathrm{a}$ & 8 \\
\hline \multirow[t]{2}{*}{$6-\mathrm{m}$ pruning } & 7.6 & 3.2 & $12.6 \mathrm{a}$ & $6.3 \mathrm{ab}$ & 8 \\
\hline & NS & NS & $*$ & $*$ & NS \\
\hline \multicolumn{6}{|c|}{ Average fruit size ( $g$ ) } \\
\hline Control & 242 & $202 \mathrm{~b}$ & $217 \mathrm{~b}$ & 215 & 210 \\
\hline 4-m pruning & 233 & $199 \mathrm{~b}$ & $233 a$ & 215 & 219 \\
\hline \multirow[t]{2}{*}{$6-\mathrm{m}$ pruning } & 231 & $218 \mathrm{a}$ & $219 b$ & 218 & $244 \mathrm{a}$ \\
\hline & NS & $*$ & $* * *$ & NS & $* * *$ \\
\hline
\end{tabular}

${ }^{\mathrm{z}}$ Mean separation in columns by Tukey-Kramer method, $P \leq 0.05$.

ns, ${ }^{*},{ }^{* *}$ Nonsignificant or significant at $P \leq 0.05$ or $\leq 0.001$, respectively.

appeared to alter the relationship between crop load and fruit size. Despite increased yields on some branches, average fruit size was either similar or larger on pruned than on control trees.

\section{Discussion}

The primary objective of this research was to develop pruning techniques to reduce tree height without reducing tree yields. This was achieved with the 6-m, but not the 4-m pruning height. A second consideration was to redistribute fruit production within the available canopy when reduced markedly by height control. This was achieved on the 4-m trees, which produced $80 \%$ of their crop in the $2-4-\mathrm{m}$ zone, and had twice as many fruit in this zone as did the 6-m and control trees. Although total fruit production was reduced by pruning trees to $4 \mathrm{~m}$, lower picking costs and reduced rejects would have offset some of this. Also, earlier intervention, by pruning trees before they became very large and overcrowded with branches would be the preferred option, thus avoiding the necessity to remove large sections of fruiting canopy.

A third objective in this trial was to reduce the number of large scaffold branches, to reduce their mutual shading in order to increase their productivity. More fruit on fewer branches would indicate an improved efficiency in fruit production through a shift in partitioning of carbon resources away from the vegetative growth of scaffold branches and toward fruiting. This objective appeared to be achieved in response to our pruning treatments, with increased branch productivity. Also, we mea- sured responses immediately following rather gross changes to the tree canopies. Although we had 3 years' data following pruning, we can speculate that the limbs and "shorter" trees may still increase further in productivity, assuming continued maintenance pruning to retain the initial benefits from reduced shading.

In New Zealand, 'Hass' avocado trees flower in October and November (Thorp et al., 1998). Fruit set in the Bay of Plenty sometimes are retained on the tree for at least 12 months before being harvested from late winter through summer (September to January). In our trial, pruning treatments were applied after harvest, in February and March, when the new season's fruit were 2-3 months old. Pruning at this time, when the summer growth flush has ceased, is less likely to stimulate excessive regrowth before winter. It would also ensure more light into the canopy at the time of floral initiation in April and May, and the formation of next year's crop (Thorp et al., 1994). Pruning in late summer may also be less disruptive to root systems as it is done after the main flush of root growth (Thorp et al., 1998). The alternative of pruning in late winter, before flowering, is only possible if the previous season's crop has been harvested.

Pruning appeared to reduce alternate bearing. Although not statistically significant, there was a trend for decreasing intensity of deviation in yield (I) with increasing severity of pruning in the 3 years following pruning ( $\mathrm{I}=$ $0.43,0.36$, and 0.30 for the control, $6-\mathrm{m}$ and 4 m pruning treatments, respectively) (Monselise and Goldschmidt, 1982). Although the eco- nomic benefit of reduced alternate bearing in fruit trees is difficult to measure, it is generally accepted that consistent yields enable the orderly marketing of fruit and increased orchard profitability. Reducing alternate bearing will reduce the risks of over-cropping and the production of large numbers of small fruit. We found some evidence of this, with more undersize fruit produced on the control than on the pruned trees. Also, pruning to reduce tree size and shading in crowded blocks would delay the need for tree removal and thus provide further economic benefit. Pest and disease control and monitoring would also be more effective with smaller trees.

Safety regulations and labor costs help determine the economic benefits of implementing pruning systems. Harvesting fruit from the upper canopy eventually gives a diminishing rate of return, especially if labor costs are relatively high and fruit become more difficult to pick. Orchard contour will also affect harvesting and grove management costs. If slopes are too steep, machinery cannot be used for harvesting. With occupational safety regulations likely to become more restrictive, harvesting fruit above a certain height may be prohibited. For practical reasons of efficient labor utilization, we chose $4 \mathrm{~m}$ as the maximum pruning height for harvesting fruit from the ground using 3-m ladders. On flat land and with mechanical ladders capable of reaching $5 \mathrm{~m}$, we chose $6 \mathrm{~m}$ as the maximum pruning height for fruit harvests. These are the heights at which pruning cuts are made. The final fruiting canopies would be $0.5-1.0 \mathrm{~m}$ above these.

Pruning height is not only limited by the height at which fruit can be harvested, but also by the height at which the pruning operation itself can be undertaken. Because avocado wood is relatively soft, most of the pruning in this trial was done using hand-held pruning saws. Chain saws were used in the first 2 years when large branches were being removed, but generally these were not required for maintenance pruning in subsequent years.

Maintenance pruning was done to prevent regrowth around pruning cuts shading lower parts of the canopy, a problem highlighted by Crane et al. (1992). We encountered a similar situation, not only from excessive vegetative regrowth but also from the continued growth of fruiting laterals that tended to form an "umbrella' over the branches below them. Our pruning technique was adjusted to space these lateral branches to prevent one branch from layering on top of another. There remains, however, the need to develop a better renewal pruning system to keep the upper portions of the canopy on large branches narrower than the lower portions to make the best use of available light (Stassen et al., 1999).

In this study, we worked with large trees with large volumes of unproductive, shaded canopy. For the development of small-tree orchard systems that better utilize available light and orchard space, we believe the future is with the development of single axis avocado trees as suggested by Stassen and Snijder (1999). Such trees would comprise the equiva- 
lent of one large scaffold branch in our present study. By avoiding or minimizing within-canopy shading, single axis trees would invest less energy in the production of structural wood and thus enable increased partitioning to fruit growth and economic yield. Our results demonstrated the potential to reduce the number of scaffold branches and produce more fruit from less wood. This result needs to be extended to singleaxis trees in high-density plantings.

\section{Literature Cited}

Ashenkasi, Y. 1984. Field assay in avocado topping-Interim report. (in Hebrew.) Alon Hanotea 38 (english translation by Y. Ashenkasi).

Bertin, Y. 1976. La taille de l'avocatier à la Martinique. Fruits 32 (6):391-399.

Crane, J.H., B. Schaffer, T.L. Davenport, and C. Balerdi. 1992. Rejuvenation of a mature, nonproductive 'Lula' and 'Booth 8' avocado grove by topping and tree removal. Proc. Fla. State Hort. Soc. 105:282-285.

Farré, J.M., J.M. Hermosa, and F. Pliego. 1987. Effects of pre-bloom pruning on leaf nutrient status, growth and cropping of the avocado cv. Hass. Proc. First World Avocado Cong. Pretoria, 1987:71-72.

Gaillard, J.P. 1971. Essai de conduite de l'avocatier en haie fruitiere. Fruits 26 (6):443-448.

Goodall, G.E. 1954. Orchard management-It's the little things that count. Calif. Avocado Soc. Yrbk. 1953-54:107-111.

Hallé, F., R.A.A. Oldeman, and P.B. Tomlinson. 1978. Tropical trees and forests-An architectural analysis. Springer, Berlin.

Monselise, S.P. and E.E. Goldschmidt. 1982. Alternate bearing in fruit trees. Hort. Rev. 4:128-173.

Stassen, P.J.C. and B. Snijder. 1999. Results with spacing, tree training and orchard maintenance in young avocado orchards. Rev. Chapingo Ser. Hort. 5 Núm. Especial:159-164.

Stassen, P.J.C., B. Snijder, and Z.J. Bard. 1999.
Results obtained by pruning overcrowded avocado orchards. Rev. Chapingo Ser. Hort. 5 Núm. Especial, p. 165-171.

Thorp, T.G. 1993. A study of modular growth in avocado (Persea americana Mill.). PhD Diss., Univ. of Adelaide, Australia.

Thorp, T.G., P. Anderson, and M.J. Camilleri. 1998. Avocado tree growth cycles-A quantitative model, p. 76-79. In: Proc. World Avocado Congr. III, 22-27 Oct. 1995, Agr. Res. Org. Bet Dagan, Israel.

Thorp, T.G., D. Aspinall, and M. Sedgley. 1994. Preformation of node number in vegetative and reproductive proleptic shoot modules of Persea (Lauraceae). Ann. Bot. 73:13-22.

Thorp, T.G. and M. Sedgley. 1993. Architectural analysis of tree form in a range of avocado cultivars. Scientia Hort. 53:85-98.

Warneke, J.E., T.W. Embleton, and S.J. Richards. 1972. Effect of rootstock propagation, nitrogen fertilization, and top pruning on Bacon avocados. Calif. Avocado Soc. Yrbk. 1971-72:110-112. 